\title{
Facile Synthesis of Hollow Flower-Like SnO and Applications in Lithium Ion Batteries
}

\author{
Yuxi Guo ( $\nabla$ guoyuxi_nwu@163.com ) \\ Panpan Xu \\ Henan University of Science and Technology \\ Manzhang $\mathrm{Xu}$ \\ Northwestern Polytechnical University \\ Ken Deng \\ Northwest University \\ Zhiyong Zhang \\ Northwest University \\ Yingnan Wang \\ Northwest University \\ Wu Zhao \\ Northwest University
}

Northwest University https://orcid.org/0000-0002-5761-587X

\section{Research Article}

Keywords: SnO, Semiconductors, Hollow-flower, Microstructure, Lithium ion batteries

Posted Date: February 26th, 2021

DOI: https://doi.org/10.21203/rs.3.rs-242937/v1

License: (c) (i) This work is licensed under a Creative Commons Attribution 4.0 International License.

Read Full License 
Facile Synthesis of hollow flower-like SnO and Applications in Lithium Ion

\section{Batteries}

Yuxi Guo ${ }^{\mathrm{a}}$, Panpan $\mathrm{Xu}^{\mathrm{b}}$, Manzhang $\mathrm{Xu}^{\mathrm{c}}$, Ken Deng ${ }^{\mathrm{a}}$, Zhiyong Zhang ${ }^{\mathrm{a}}$, Yingnan Wang $^{\mathrm{a}}$ and $\mathrm{Wu} \mathrm{Zhao}^{\mathrm{a}^{*}}$

${ }^{\text {a }}$ School of Information Science and Technology, Northwest University, Xi'an 710127, P. R. China

${ }^{\mathrm{b}}$ School of Materials Science and Engineering, Henan University of Science and Technology, Luoyang 471023, P. R. China

${ }^{c}$ Institute of Flexible Electronics, Northwestern Polytechnical University, 127 West Youyi Road, Xi'an, 710072, P. R. China.

E-mail: zhangzy@nwu.edu.cn (Z. Zhang), zhaowu@nwu.edu.cn (W. Zhao). Telephone: +8602988308280

ABSTRACT: Novel hollow flower-like $\mathrm{SnO}$ structures have been successfully synthesized by using a facile solvothermal method approach, which injecting $\mathrm{LiN}\left(\mathrm{SiMe}_{3}\right)_{2}$ to the solution of $\mathrm{SnCl}_{2}$ and oleamine. The as-synthesized hollow flower-like $\mathrm{SnO}$ structures were aggregated by ultrathin $\mathrm{SnO}$ nanosheets with large surface area and exhibit narrow size distribution of $\sim 2.0 \mu \mathrm{m}$. The electrochemical performance of hollow flower-like $\mathrm{SnO}$ structures were examined as an anode material in coin cells for lithium-ion batteries. It demonstrates excellent lithium ion batteries performance as characterized by the cycling stability, specific capacity, cyclic voltammetry and rate performance. The measured discharge capacity is 361.4 $\mathrm{mAh} \mathrm{g}^{-1}$ after 50 charge/discharge cycles with $46 \%$ capacity retention, which indicated a improving in cyclic stability. This result demonstrated that the specific hollow structure has great potential as the electrodes for lithium ion batteries. This 
work may provide an attractive road to synthesize other hollow-flower structures of transition metal oxides.

Keywords: SnO; Semiconductors; Hollow-flower; Microstructure; Lithium ion batteries

\section{Introduction}

In recent years, lithium ion battery (LIBs) is one of the most advanced energy storage systems which have been widely studied for cell phones, handheld computers portable, electronic vehicles and biomedicine, due to their characteristics of eco-friendly, high energy density and long cycle life. Many attempts have been conducted to develop potential materials (theoretical capacity higher than traditional graphite) as candidates to replace the currently commercial graphite anode materials, such as metal nitrides, metal oxides, metal sulfide and alloys. Recently, Sn-based anode materials have been widely used in LIBs due to their high theoretical capacity, low cost and low potential for lithium alloying. SnO is p-type semiconductor (direct band gap of $2.5-3.4 \mathrm{eV}^{[1,2]}$ ) which has been utilized in catalyst ${ }^{[3-6]}$, sensor ${ }^{[7,8]}$ and energy storage ${ }^{[9,10]}$. It is noteworthy that the theoretical capacity of $\mathrm{SnO}$ is $875 \mathrm{mAh} \mathrm{g}^{-1}$, which is higher than $\mathrm{SnO}_{2}\left(783 \mathrm{mAh} \mathrm{g}^{-1}\right)$. This suggests that $\mathrm{SnO}$ is a potential cathode material for lithium ion batteries. As known, the properties of materials have been strong influenced on their sizes and morphologies. In recent research reports, $\mathrm{SnO}$ with various morphologies morphologies have been reported, such as diskettes, platelets, sheets, belts and flowers ${ }^{[3,6,9]}$. Due to the higher active specific areas and short path lengths for electronic transport, nanostructured $\mathrm{SnO}$ is supposed to be more suitable for long-lived anode materials.

In this work, we successfully prepared hollow flower-like $\mathrm{SnO}$ through the reaction of $\mathrm{SnCl}_{2}$ and $\mathrm{LiN}\left(\mathrm{SiMe}_{3}\right)_{2}$ in oleamine. The hollow flower-like structures provides vast 
surface states and defects with high surface area and accelerates the transport of conductive ions. On the other hand, the volume changes associated with $\mathrm{Li}^{+}$insertion and extraction can be well buffered due to the hierarchical structure. Benefiting from the structural features, the hollow flower-like $\mathrm{SnO}$ delivers an initial discharge capacity of $1235.8 \mathrm{mAh} \mathrm{g}^{-1}$, and remains $361.4 \mathrm{mAh} \mathrm{g}^{-1}$ after 50 cycles. The results demonstrate a significantly improving in cyclic stability. In this sense, the hierarchical structure holds promise for anode material for rechargeable lithium ion batteries.

\section{Materials and methods}

$\mathrm{SnCl}_{2}$ (purity 98\%), Lithium bis(trimethylsilyl)amide ( $\mathrm{LiN}\left(\mathrm{SiMe}_{3}\right)_{2}$, purity $95 \%$ ), oleylamine ( assay $\geq 70 \%$ ) were all purchased from Sigma Aldrich. Toluene, ethanol, and chloroform were obtained from commercial sources. All chemicals were used without further purification. In a typical synthesis, $\mathrm{SnCl}_{2}(0.125 \mathrm{mmol})$ and oleyamine $(5.0 \mathrm{~g})$ were loaded into a $50 \mathrm{ml}$ three-neck flask and then heated to $180{ }^{\circ} \mathrm{C}$. Next, a prepared clear solution containing $\mathrm{LiN}\left(\mathrm{SiMe}_{3}\right)_{2}(0.9 \mathrm{mmol})$ and toluene $(1.0 \mathrm{ml})$ was quickly injected into the flask. The reaction was kept at $180{ }^{\circ} \mathrm{C}$ for 30 min under stirring. Then, the flask was cooled to room temperature naturally. Toluene and ethanol were added to the reaction solution, and the resulting particles were precipitated by centrifugation. The collected $\mathrm{SnO}$ samples finally dispersed in chloroform for characterization.

CR-2430 coin cells were assembled with pure lithium foil as the counter and reference electrode in glove box under $\mathrm{N}_{2}$ atmosphere. The working electrode contains SnO samples, acetylene black and polyvinylidene fluoride (PVDF) in weight ratio of 50:30:20, and pasted on a $14 \mathrm{~mm}$ nickel foam. The electrolyte was $1 \mathrm{M} \mathrm{LiPF}_{6}$ dissolved in a mixture of dimethyl carbonate, diethyl carbonate, and ethylene carbonate (1:1:1 by volume), and the separator was microporous polypropylene film. 
Cells were constructed in a glove box in argon atmosphere under a dew point below $-65^{\circ} \mathrm{C}$.

The samples were examined by X-ray diffraction (XRD, Shimadzu 6100). The Raman spectrum was produced at room temperature with HORIBA Xplora Plus Raman Microscope. Scanning electron microscopy (SEM) was performed on Zeiss IIGMA/VP at $3 \mathrm{kV}$. The transmission electron microcopy (TEM), high resolution TEM (HRTEM) and selected area electron diffraction (SAED) were determined using JEM-3010 at $200 \mathrm{kV}$. The charge/discharge tests were carried out on a LAND battery program-control test system (CT 2001A, Wuhan Jinnuo Electronic). Cyclic voltammetry (CV) and electrochemical impedance spectroscopy (EIS) were carried out by CHI660D electrochemical workstation.

\section{Results and discussion}

The morphology of as-synthesized $\mathrm{SnO}$ was characterized by SEM, which shown in Figure 1a-b. It can be observed that the $\mathrm{SnO}$ exhibits a uniform particle size of $\sim 2.0$ $\mu \mathrm{m}$. High-magnification SEM image indicates that the specific hollow flower-like $\mathrm{SnO}$ was aggregated by single-crystalline $\mathrm{SnO}$ nanosheets. The crystal structures of as-synthesized samples were examined by XRD, as shown in Figure 1c. The peaks in XRD are attributed to (101), (110), (002), (200), (112), (211), (202), (103) diffraction lines, respectively. All the diffraction peaks of $\mathrm{SnO}$ are consistent with JCPDS Card No. 06-0395 (tetragonal SnO phases, lattice constants $a=b=3.8029 \AA, c=4.8382 \AA$, c/a $=1.27$ ), which suggests that high purity $\mathrm{SnO}$ had been synthesized. The relatively sharp diffraction peaks indicate good crystallinity and micro-sized particles of the SnO products. In addition, Raman spectrum (Figure 1d) demonstrates two Raman modes at $113 \mathrm{~cm}^{-1}\left(\mathrm{E}^{\mathrm{g}(1)}\right)$ and $212 \mathrm{~cm}^{-1}\left(\mathrm{~A}^{1 \mathrm{~g}}\right)$, showing the c-axis polarization ${ }^{[11]}$.

The EDS spectrum (Figure 2a) indicated that only $\mathrm{Sn}$ and $\mathrm{O}$ elements are detected. 
The atom ration is $49.43: 50.57$, close to $1: 1$, exhibiting the stoichiometric phase $\mathrm{SnO}$. Moreover, the EDS line-scan intensity profile across the single SnO sample was shown in Figure 2b. The element of $\mathrm{O}$ and $\mathrm{Sn}$ exhibit weak but nonzero intensity in core region of the structure, which indicated the hollow structure of aggregated $\mathrm{SnO}$ nanosheets. TEM and HRTEM were carried out to investigate the structure and crystallography of as-synthesized $\mathrm{SnO}$ nanostructure, which shown in Figure 2c-d. The TEM image demonstrates a lighter color region at the central of the single SnO nanostructure, which further verify the hollow structure of the sample. HRTEM shows that the interfringe spacing of the crystallographic planes is about $0.27 \mathrm{~nm}$, corresponding to the interplanar distance of (110) lattice planes of tetragonal $\mathrm{SnO}$. Meanwhile, the corresponding SAED pattern can be indexed as the [001] zone axis of tetragonal SnO. Due to the grains have the slowest growth velocity along the direction of $<001>$, the formation of SnO crystals mainly exhibits a (001) face ${ }^{[12]}$.

A probable growth mechanisms of the as-synthesized hollow-flower $\mathrm{SnO}$ structures is proposed, which shown in Figure 3. Initially, $\mathrm{SnCl}_{2}$ reacted with $\mathrm{Li}\left[\mathrm{N}\left(\mathrm{SiMe}_{3}\right)_{2}\right]$ to form $\mathrm{Sn}\left[\mathrm{N}\left(\mathrm{SiMe}_{3}\right)_{2}\right]_{2}$ which will form $\mathrm{SnO}$ nuclei through reduction reaction. Driven by the minimization of the total energy of the system, the SnO nuclei then form 'petals' nanosheets in a very short time. The petals aggregated in oleyamine to assemble into hollow flower-like $\mathrm{SnO}$ nanostructure. The role of oleyamine in the synthesis is not only a solvent, but also a surfactant ${ }^{[13]}$.

To explore the potential applications in lithium batteries, the as-synthesized $\mathrm{SnO}$ were fabricated into CR-2430 coin cells as anode. The galvanostatic charge/discharge voltage profiles of first three cycles are exhibited in Figure 4a. In the first static lithiation process, the initial capacity were $1235.8 \mathrm{mAh} \mathrm{g}^{-1}$. The high initial discharge capacity is attributed to the formation of solid electrolyte interface (SEI) and the 
volume expansion when $\mathrm{SnO}$ was transformed to $\mathrm{Li}_{\mathrm{x}} \mathrm{Sn}(0 \leq \mathrm{x} \leq 4.4)$ alloy. Figure $4 \mathrm{~b}$ shows the cycling stability of as-synthesized $\mathrm{SnO}$, which the discharge capacity remained $361.4 \mathrm{mAh} \mathrm{g}^{-1}$ after 50 charge/discharge cycles. The coulombic efficiencies of $\mathrm{SnO}$ is $59.3 \%$ in the initial and increased to $97 \%$ after several cycles, which revealing a good reversibility of the $\mathrm{SnO}$ samples. In addition, the $\mathrm{SnO}$ electrode has a rate performance with reversible capacities of 537.3, 287.9, 221.6 and $122.5 \mathrm{mAh} \mathrm{g}^{-1}$ at $0.2,0.4,0.8$, and $1.6 \mathrm{C}\left(1 \mathrm{C}=500 \mathrm{~mA} \mathrm{~g}^{-1}\right)$, respectively (Figure $\left.4 \mathrm{c}\right)$. When returns to $0.2 \mathrm{C}$, the coin cell displayed a stable discharge capacity of $436.1 \mathrm{mAh} \mathrm{g}^{-1}$, indicated an excellent rate capacity. The $\mathrm{Li}^{+}$insertion-extraction behavior of $\mathrm{SnO}$ electrode was investigated by cyclic voltammetry $(\mathrm{CV})$. According to Figure $4 \mathrm{~d}$, the reduction peaks at $1.02 \mathrm{~V}$ and $0.61 \mathrm{~V}$ can be observed in the first cathodic scan, which could attributed to the $\mathrm{SnO}$ reduced to $\mathrm{Sn}$ (Eq. 1) and the irreversible formation of solid electrolyte interface. The $\mathrm{Sn}$ is then reacts with $\mathrm{Li}$ to form $\mathrm{Li}_{\mathrm{x}} \mathrm{Sn}$ alloys. The $\mathrm{Li}$ matrix can promote the alloying and de-alloying reactions resulting in better cyclic performance [14]. The peaks at 0.06 and $0.59 \mathrm{~V}$ can be ascribed to the reaction process in Eq. 2 . Furthermore, compared to the second and third cycles, the peak intensities of the first cycle are lower. This might be due to the unique hierarchical structures ${ }^{[9]}$. Compared with $\mathrm{SnO}$ of other morphologies, the $\mathrm{SnO}$ sample demonstrated excellent cyclic stability of lithium ion batteries, which is shown in Table. 1. The excellent electrochemical performance of hollow-flower $\mathrm{SnO}$ can be ascribed to vast surface states and defects with high surface area on hollow-flower SnO accelerating the transport of conductive ions.

$$
\begin{aligned}
& \mathrm{SnO}+2 \mathrm{e}^{-}+2 \mathrm{Li}^{+} \rightarrow \mathrm{Sn}+\mathrm{Li}_{2} \mathrm{O} \\
& \mathrm{Sn}+x \mathrm{e}^{-}+x \mathrm{Li} \rightarrow \mathrm{Li}_{x} \mathrm{Sn}(0 \leq x \leq 4.4)
\end{aligned}
$$

Table. 1 Performance comparison of SnO lithium ion battery with different 
morphologies

\begin{tabular}{ccccc}
\hline Morphology & 20 cycles & 40 cycles & 50 cycles & Refer. \\
\hline meshes & $320 \mathrm{mAh} / \mathrm{g}^{-1}$ & $/$ & $/$ & {$[15]$} \\
nanoflowers & $450 \mathrm{mAh} / \mathrm{g}^{-1}$ & $/$ & $/$ & {$[16]$} \\
nanoplatelets & $/$ & $321 \mathrm{mAh} \mathrm{g}^{-1}$ & $/$ & {$[17]$} \\
nanosheets & $559 \mathrm{mAh} / \mathrm{g}^{-1}$ & $/$ & $305.4 \mathrm{mAh} \mathrm{g}^{-1}$ & {$[18]$} \\
hollow-flowers & $459.5 \mathrm{mAh} \mathrm{g}^{-1}$ & $384.5 \mathrm{mAh} \mathrm{g}^{-1}$ & $361.4 \mathrm{mAh} \mathrm{g}^{-1}$ & This work \\
\hline
\end{tabular}

\section{Conclusions}

In our work, $\mathrm{SnO}$ with hollow flower-like structures were prepared and the lithium ion batteries properties of samples were studied. Compared with $\mathrm{SnO}$ of other morphologies, the $\mathrm{SnO}$ sample demonstrated excellent cyclic stability of lithium ion batteries. The lithium ion battery performance enhancement can be ascribed to vast surface states and defects with high surface area on hollow flower-like SnO. Our work can be used to extend the synthesis of other anode materials with shape-controlled hollow structure for LIBs.

\section{Acknowledgements}

This work was supported by the Key Program for International Science and Technology Cooperation Projects of Shaanxi Province (2018KWZ-08), the NWU Graduate Innovation and Creativity Funds (Grants YZZ17179).

\section{Conflicts of interest}

The authors declare no competing financial interest.

\section{References}

[1] C Guillen, J Herrero, P-type SnO thin films prepared by reactive sputtering at high deposition rates, J. Mater. Sci. Technol. in press (2019). 
[2] J Du, CX Xia, YM Liu, XP Li, YT Peng, SY Wei, Electronic characteristics of p-type transparent SnO monolayer with high carrier mobility, Appl. Surf. Sci. 401 (2017) 114-119.

[3] DH Han, YZ Wang, CH Sun, BY Liang, WX Zhang, Hydrothermal microwave synthesis of $\mathrm{SnO}$ microspheres with excellent photocatalytic activity Ceram. Int. 45 (2019) 4089-4093.

[4] JK Lee, YK Kim, BJ Choi, TM Chung, JH Han, SnO-decorated $\mathrm{TiO}_{2}$ nanoparticle with enhanced photocatalytic performance for methylene blue degradation, Appl. Surf. Sci. 480 (2019) 1089-1092.

[5] ZJ Su, YB Zhang, BL Han, BB Liu, MM Lu, ZW P, GH Li, T Jiang, Synthesis, characterization, and catalytic properties of nano-SnO by chemical vapor transport (CVT) process under CO-CO2 atmosphere, Mater. Design. 121 (2017) 280-287.

[6] JH Kim, KM Jeon, JS Park, YC Kang, Excellent Li-ion storage performances of hierarchical $\mathrm{SnO}-\mathrm{SnO}_{2}$ composite powders and $\mathrm{SnO}$ nanoplates prepared by one-pot spray pyrolysis, J. Power Sources 359 (2017) 363-370.

[7] S Rezalou, T Öznülüer, Ü Demir, One-Pot electrochemical fabrication of Single-Crystalline $\mathrm{SnO}$ nanostructures on $\mathrm{Si}$ and ITO substrates for Catalytic, sensor and energy storage applications, Appl. Surf. Sci. 448 (2018) 510-521.

[8] H Yu, TY Yang, ZY Wang, ZF Li, Q Zhao, MZ Zhang, p-n heterostructural sensor with $\mathrm{SnO}-\mathrm{SnO}_{2}$ for fast $\mathrm{NO}_{2}$ sensing response properties at room temperature, Sensor. Actuat. B-Chem. 258 (2018) 517-526.

[9] J Zeng, CQ Peng, RC Wang, YJ Liu, XF Wang, J Liu, Large-scale synthesis of hierarchical SnO spheres assisted with poly (Nisopropylacrylamide) for high lithium storage capacity, Ceram. Int. 45 (2019) 1246-1250.

[10] Z Bian, A Li, RY He, HH Song, XH Chen, JS Zhou, ZK Ma, Metal-organic 
framework-templated porous $\mathrm{SnO} / \mathrm{C}$ polyhedrons for high-performance lithium-ion batteries, Electrochim. Acta 289 (2018) 389-396.

[11] YQ Guo, RQ Tan, X Li, JH Zhao, ZL Luo, C Gao, WJ Song, Shape-controlled growth and single-crystal XRD study of submillimeter-sized single crystals of $\mathrm{SnO}$, CrystEngComm 13 (2011) 5677.

[12] S Wang, S Xie, H Li, S Yan, K Fan, M Qiao, Solution route to single crystalline SnO platelets with tunable shapes, Chem. Commun. 4 (2005) 507-509.

[13] E Boccalon, G Gorrasi, M Nocchetti. Layered double hydroxides are still out in the bloom: Syntheses, applications and advantages of three-dimensional flower-like structures. Adv. Colloid Interface Sci., 2020, 285.

[14] Y Idota, T Kubota, A Matsufuji, Y Maekawa, T Miyasaka, Tin-Based Amorphous Oxide: A High-Capacity Lithium-Ion-Storage Material, Science, 276 (1997) 1395.

[15] H Uchiyama, E Hosono, I Honma, HS Zhou, H Imai, A Nanoscale Meshed Electrode of Single-crystalline $\mathrm{SnO}$ for Lithium-ion Rechargeable Batteries, Electrochem. Commun. 10 (2008) 52-55.

[16] J Ning, Q Dai, T Jiang, K Men, D Liu, N Xiao, C Li, D Li, B Liu, B Zou, G Zou, WW Yu, Facile Synthesis of Tin Oxide Nanoflowers: A Potential High-Capacity Lithium-Ion-Storage Material, Langmuir, 25, (2009) 1818-1821.

[17] YJ Hu, KX Xu, LY Kong, H Jiang, L Zhang, CZ Li, Flame synthesis of single crystalline SnO nanoplatelets for lithium-ion batteries, Chem. Eng. J. 242 (2014) 220-225.

[18] HJ Zhang, QQ He, FJ Wei, YJ Tian, Y Jiang, GH Zheng, GJ Ding, Z Jiao, Ultrathin SnO nanosheets as anode materials for rechargeable lithium-ion batteries, Mater. Lett. 120 (2014) 200-203. 

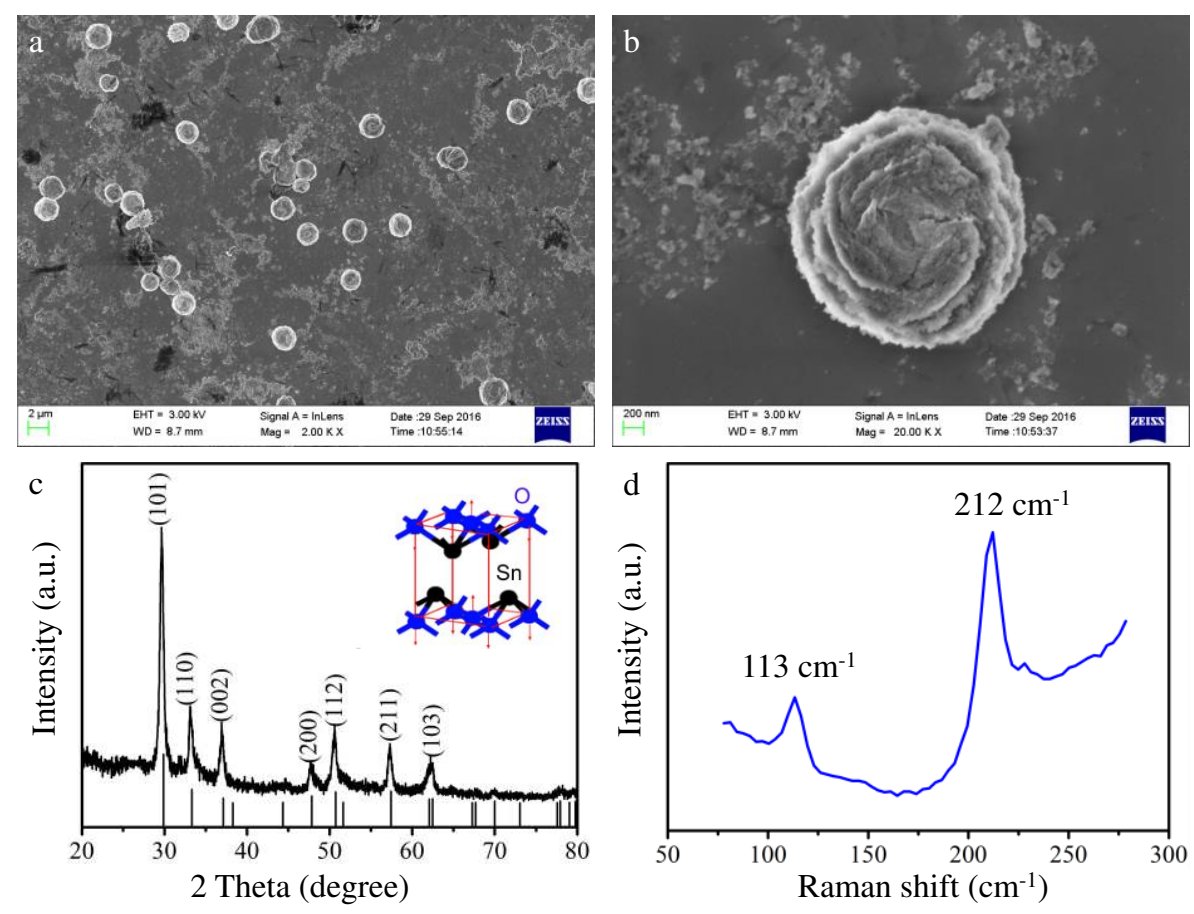

Figure 1 (a) Low- and (b) high-magnification SEM images (c) XRD pattern (d) Raman spectra of as-prepared $\mathrm{SnO}$.
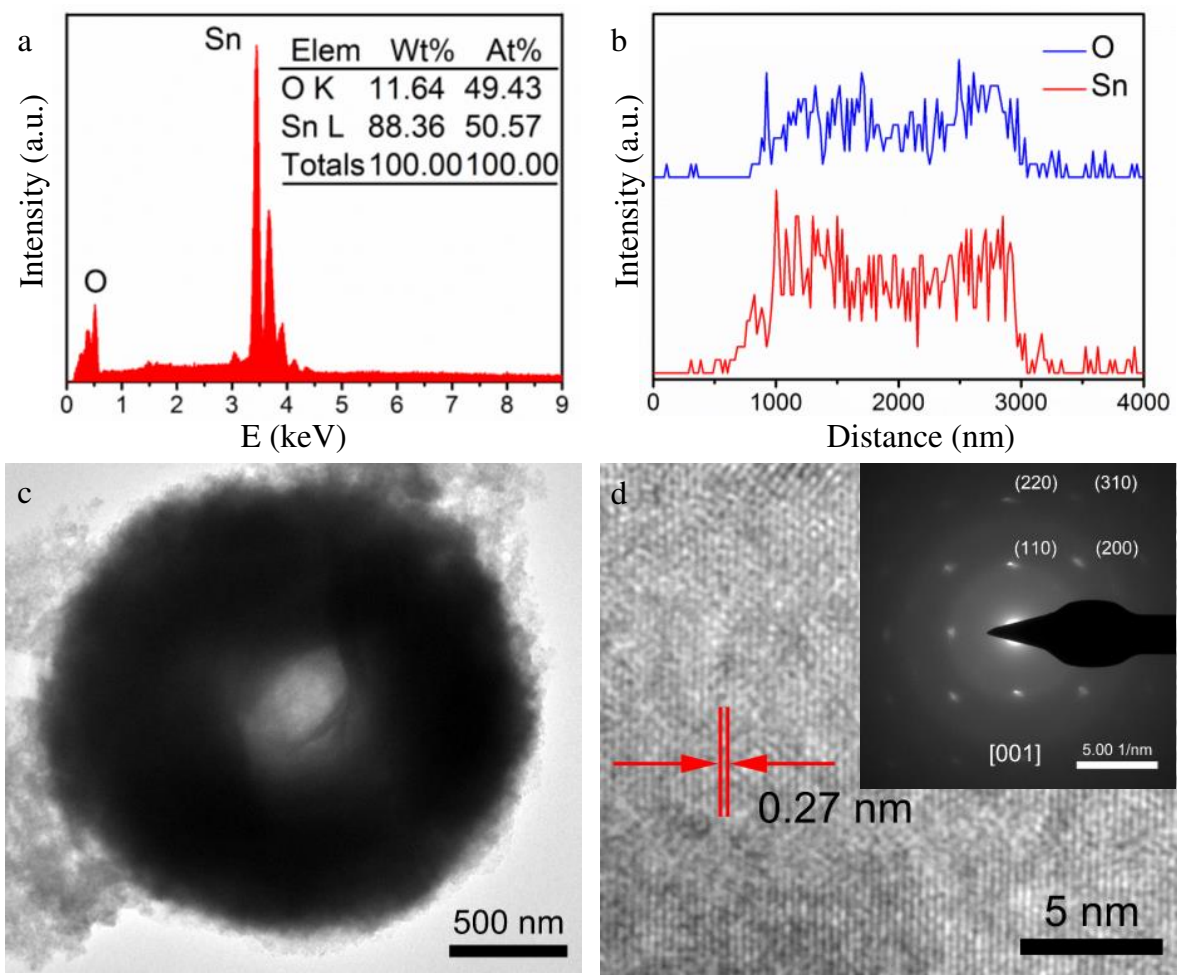

Figure 2 (a) EDS spectrum of as-prepared SnO. (b) EDS line-scan intensity profile across the single SnO sample. (c) TEM image and (d) HRTEM image (inset shows SAED pattern) of as-prepared $\mathrm{SnO}$. 


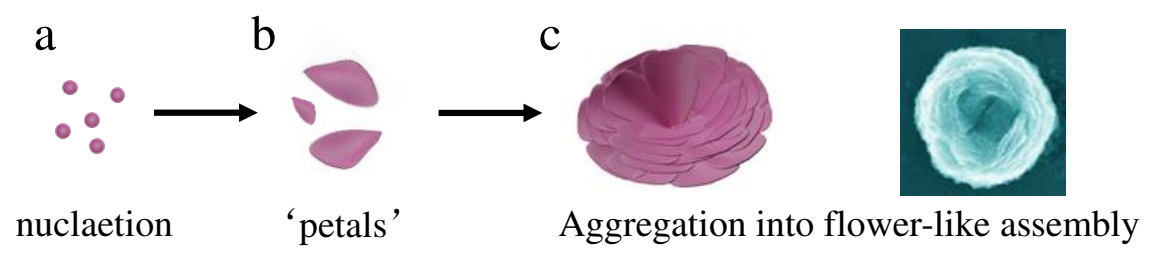

Figure 3 Scheme of hollow flower-like SnO formation.
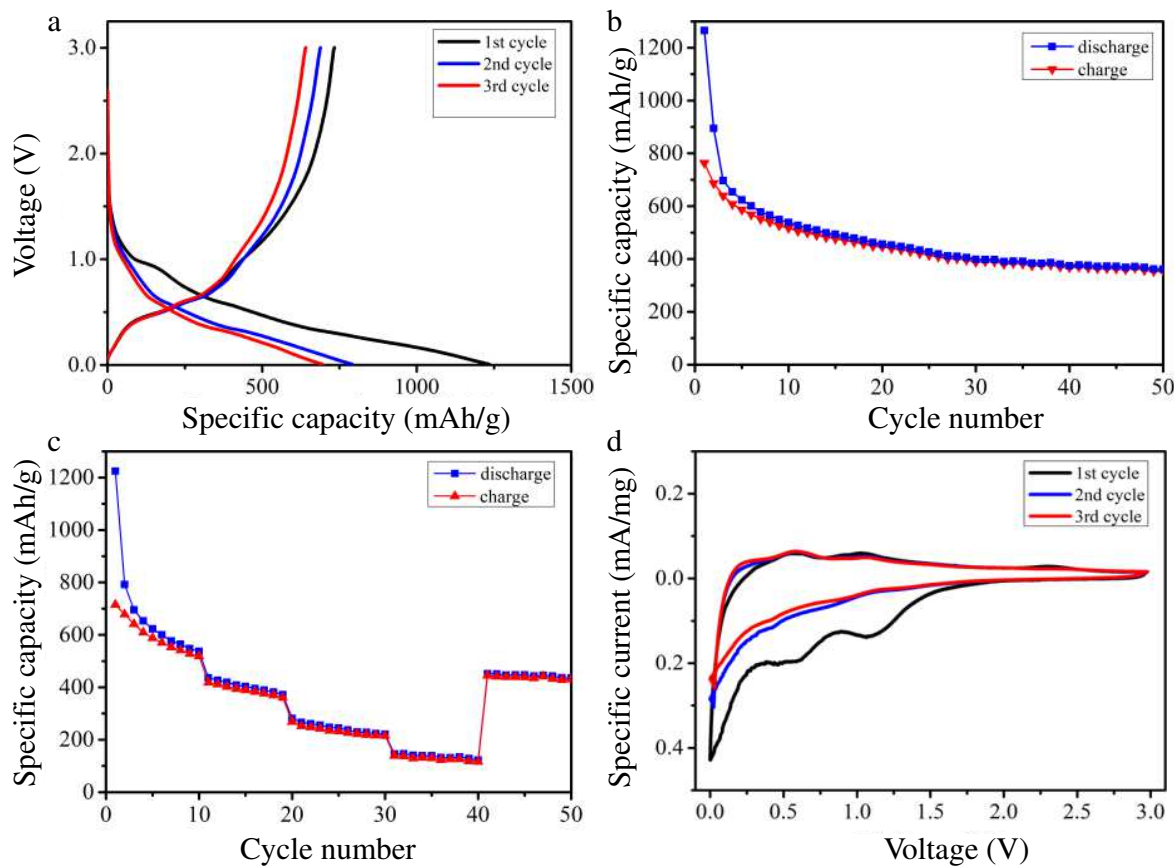

Figure 4 (a) The initial three charge-discharge Profile (b) the cycle performance (c) rate performance (d) $\mathrm{C}-\mathrm{V}$ of as-prepared $\mathrm{SnO}$. 


\section{Figures}
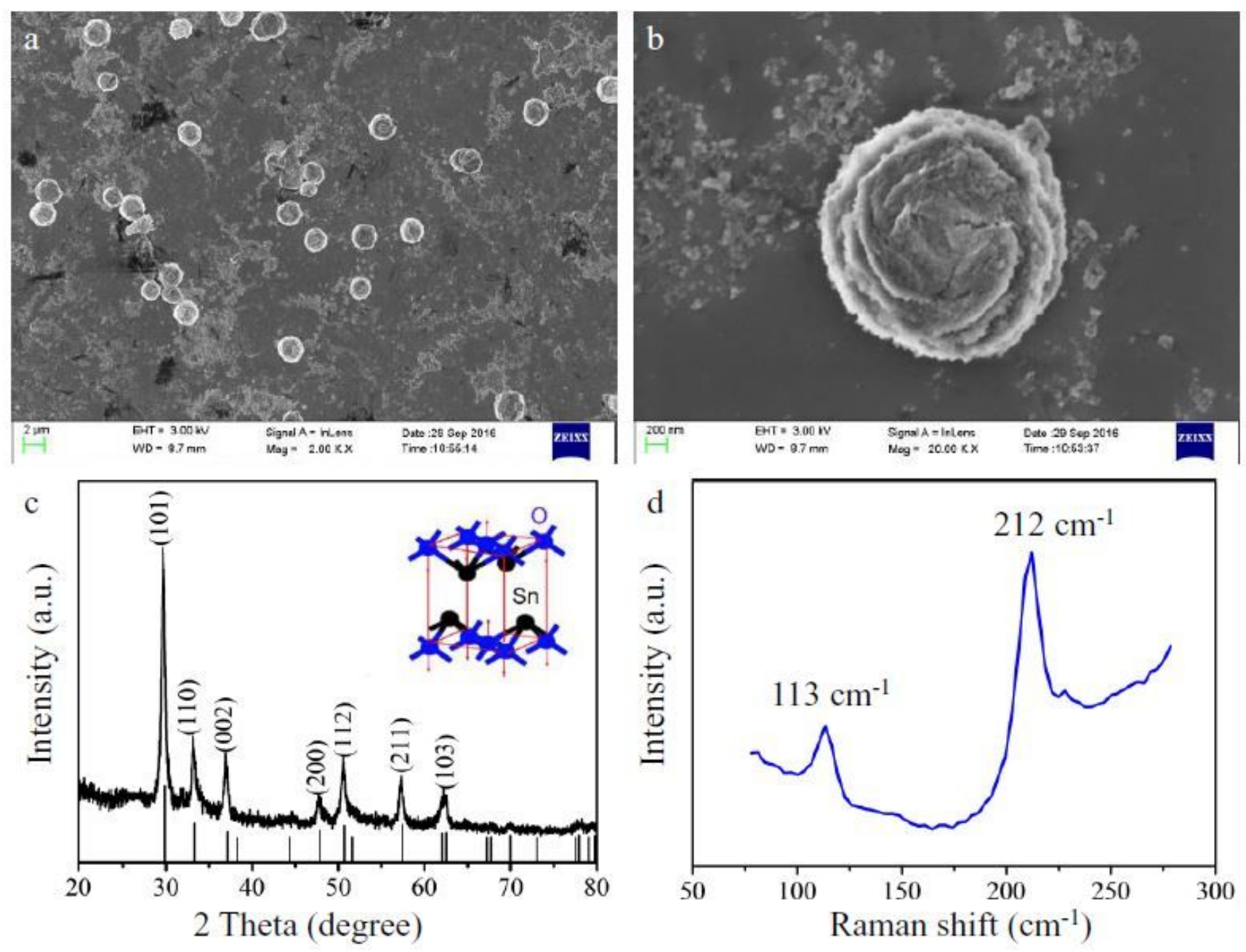

Figure 1

(a) Low- and (b) high-magnification SEM images (c) XRD pattern (d) Raman spectra of as-prepared SnO. 

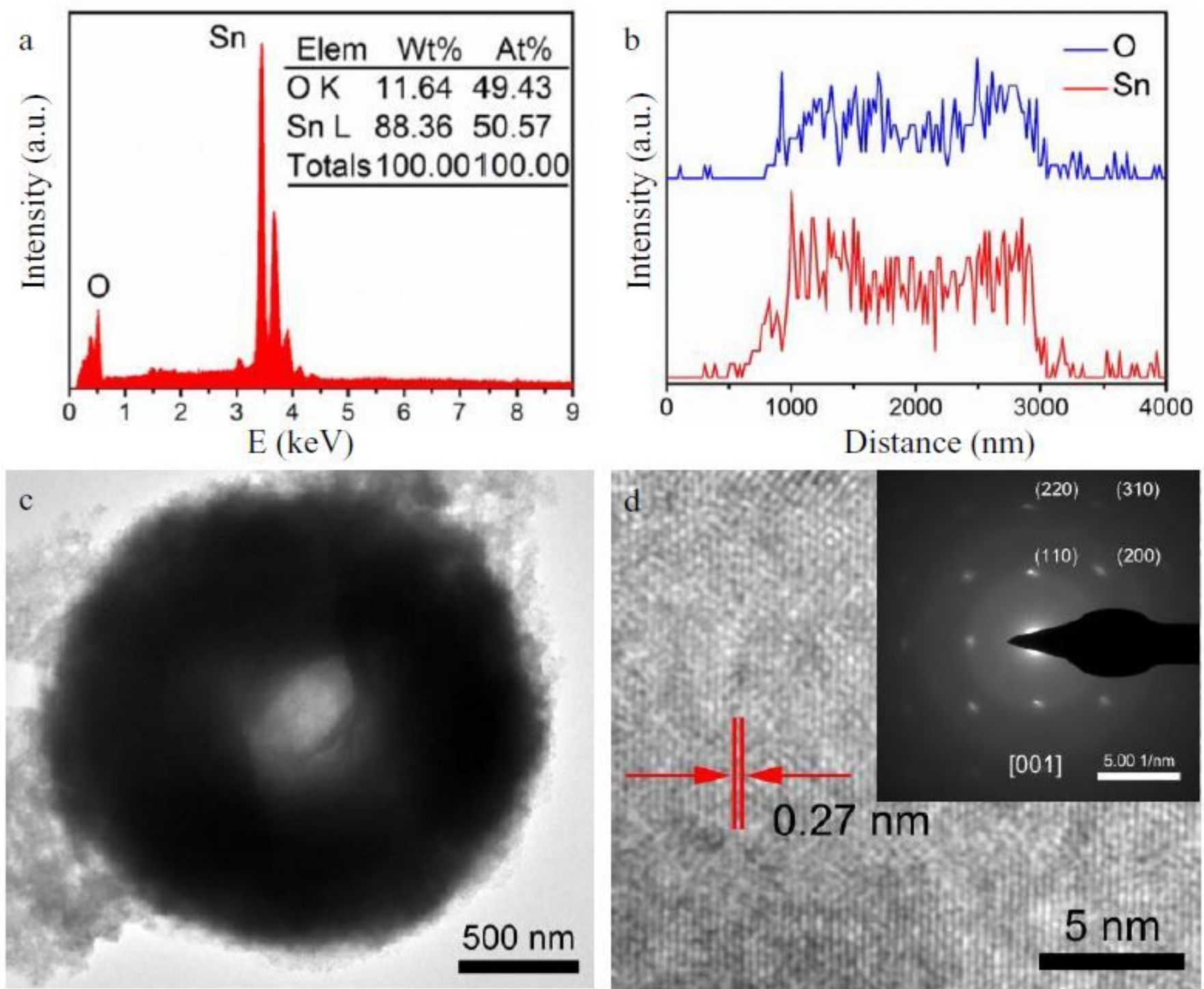

Figure 2

(a) EDS spectrum of as-prepared SnO. (b) EDS line-scan intensity profile across the single SnO sample.

(c) TEM image and (d) HRTEM image (inset shows SAED pattern) of as-prepared SnO.
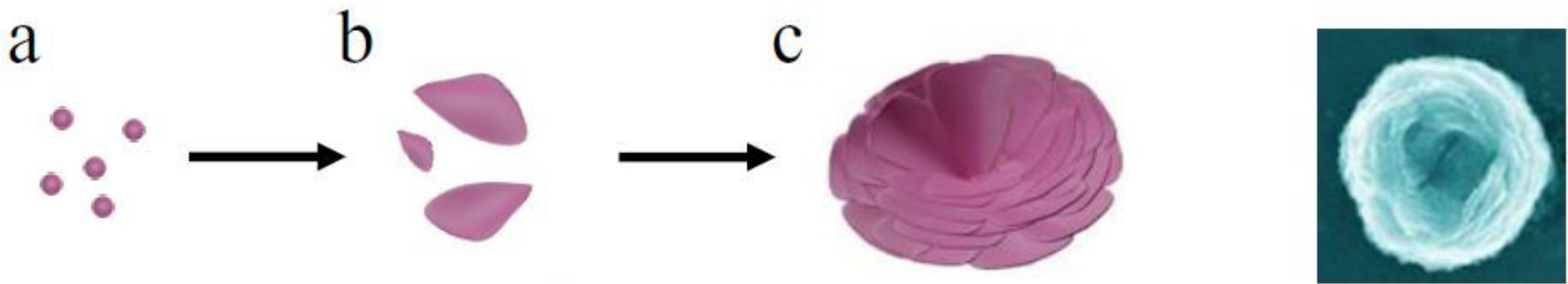

nuclaetion 'petals' Aggregation into flower-like assembly 
Figure 3

Scheme of hollow flower-like SnO formation.
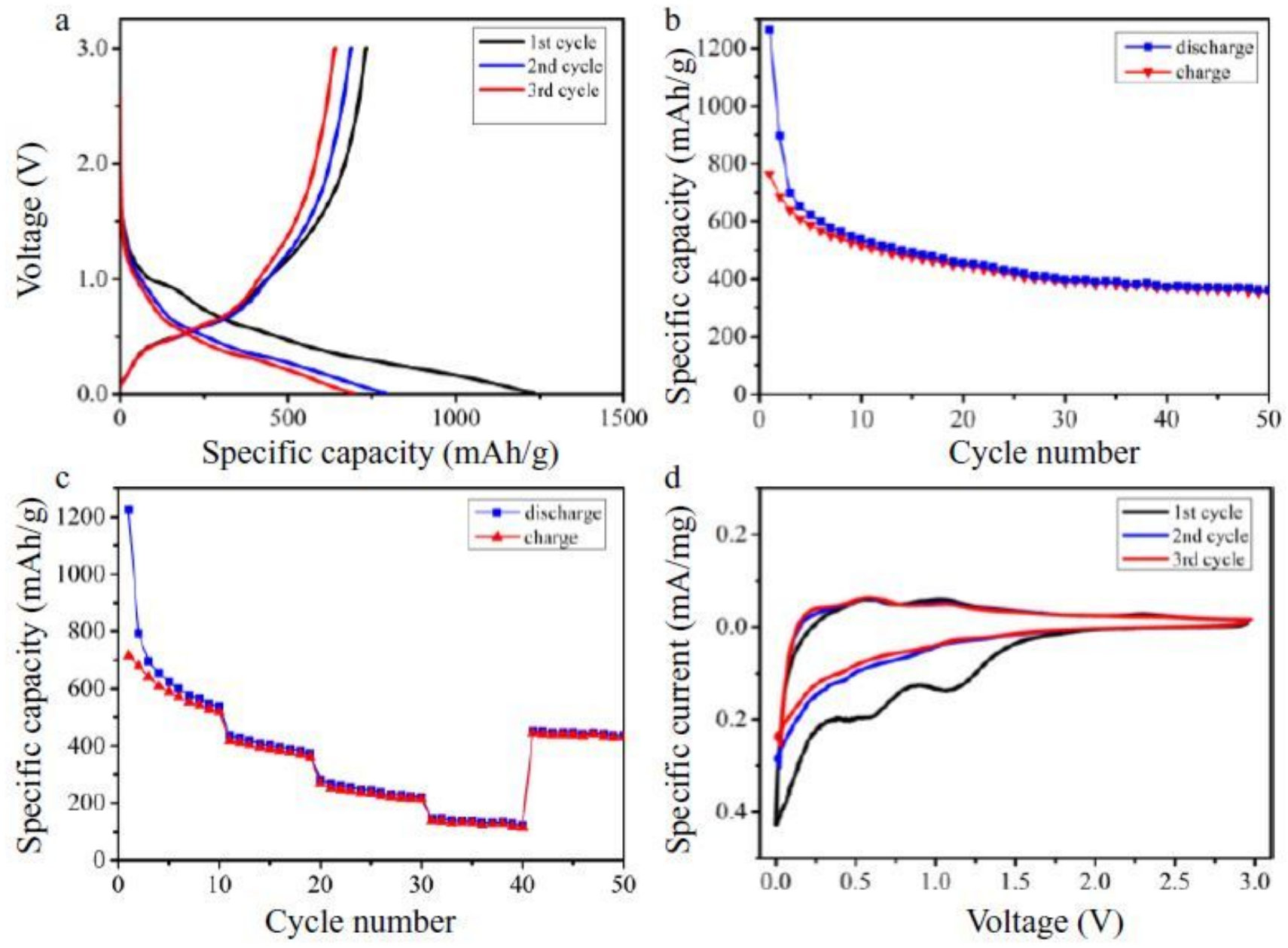

Figure 4

(a) The initial three charge-discharge Profile (b) the cycle performance (c) rate performance (d) C-V of asprepared SnO. 